\title{
Infrapatellar Fat Pad Para-Articular Osteochondroma: A Ten-Year Follow-up and Review
}

\author{
Hasan Bombaci ${ }^{1,}$; Emre Bilgin ${ }^{2}$ \\ ${ }^{1}$ Department of Orthopaedics and Traumatology, Haydarpasa Numune Education and Research Hospital, Istanbul, Turkey \\ ${ }^{2}$ Department of Orthopaedics and Traumatology, Igdir State Hospital, Igdir, Turkey \\ ${ }^{*}$ Corresponding author: Hasan Bombaci, Department of Orthopaedics and Traumatology, Haydarpasa Numune Education and Research Hospital, Istanbul, Turkey. Tel: +90-2164144502, \\ E-mail:bombacih@hotmail.com
}

Received: March 3, 2015; Accepted: March 15, 2015

\begin{abstract}
Introduction: Para-articular masses are not clear enough in terms of their etiology and nomenclature. Although surgical removal of the mass is the preferred treatment, long term follow-up after surgical treatment has not been reported yet. The current study presents a patient with the osteo-cartilaginous mass of infrapatellar region, diagnosed after a trauma. This case has the longest follow-up period in the literature.

Case Presentation: A 52-year-old female patient referred after falling down on her right knee. Lateral radiographs of the knee revealed a mass in the infrapatellar area. The case was treated surgically by total excision of the mass. The mass was extra-capsular with lobular and irregular shape. After mass removal the clinical course was uneventful and at the 10-year follow-up, no signs of recurrence were evident clinically or radiologically.

Conclusions:Tumor-like lesions within the infrapatellar fat pad should remind the para-articular osteochondroma. Although its etiology has not yet been elicited, operative removal of the mass is the preferred treatment of choice and also curative in long-term follow-up.
\end{abstract}

Keywords: Para-Articular Osteochondroma; Chondroma; Knee; Infrapatellar

\section{Introduction}

Cartilaginous loose bodies inside the knee joint are wellknown and usually arise from osteochondritis dissecans or osteochondral fractures. Another rare entity, called para-articular osteochondroma, is sometimes discussed confusingly among intra-articular loose bodies or osteochondral fractures of the tibia (1). This lesion is essentially extra-articular in the region of the infrapatellar fat pad (2). Sometimes, it becomes very large to stretch the quadriceps mechanism $(3,4)$. Its origin is unclear, therefore the terminology used to describe these para-articular masses are confusing (5-7). The literature contains several reports that call the same entity as chondroma, osteochondroma and end-stage Hoffa's disease with the longest follow-up period of approximately three years (5-8).

The current study aimed to document the lesion located in the region of infrapatellar fat pad and discuss clinical and radiological differences and similarities with those of the literature. To the authors' best knowledge, this case, with a 10-year follow-up period, has the longest follow-up period reported so far.

\section{Case Presentation}

A 52-year-old housewife referred after falling down on her right knee. Her initial symptom of discomfort on her knee had begun one year earlier when she attended the hospital. Although she complained of pain only on heavy activity for last year, she had not been aware of a swelling in her knee until falling. On physical examination, there was a hard mass on the posteromedial edge of the patellar tendon. Active range of movement of the knee was a little restricted and painful. Results of routine laboratory screening tests were unremarkable. There was no history of major or minor repetitive trauma in the past. Plain lateral radiographs of the knee revealed a well circumscribed mass in the infrapatellar area (Figure 1).

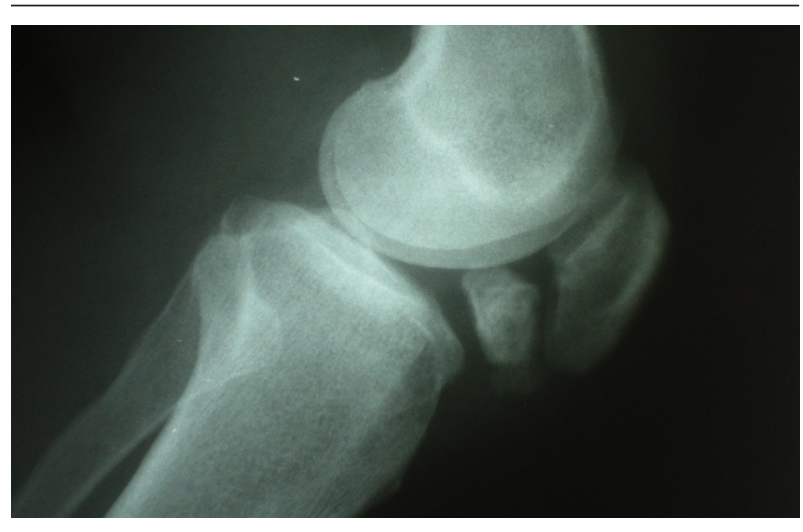

Figure 1. Lateral Radiograph of the Knee Showing an Osseous Mass in the Region of Infrapatellar Fat Pad

Copyright (c) 2015, Kashan University of Medical Sciences. This is an open-access article distributed under the terms of the Creative Commons Attribution-NonCommercial 4.0 International License (http://creativecommons.org/licenses/by-nc/4.0/) which permits copy and redistribute the material just in noncommercial usages, provided the original work is properly cited. 
The patient underwent total excision of the mass. The mass was found extra-capsular and it was adjacent to the patellar tendon. The gross appearance of the mass was lobular and irregular in shape. It approximately was $4.5 \times$
$3.5 \times 1 \mathrm{~cm}$ (Figure 2A). Histologically, the lobules consisted of well differentiated bone tissue surrounded by cartilage with evidence of enchondral bone formation at the interface suggesting osteochondroma (Figure 2B).

Figure 2. Specimen Showing (A) A lobulated surface and (B) proliferative cartilage overlying well differentiated trabecular bone (H\&E X 40)
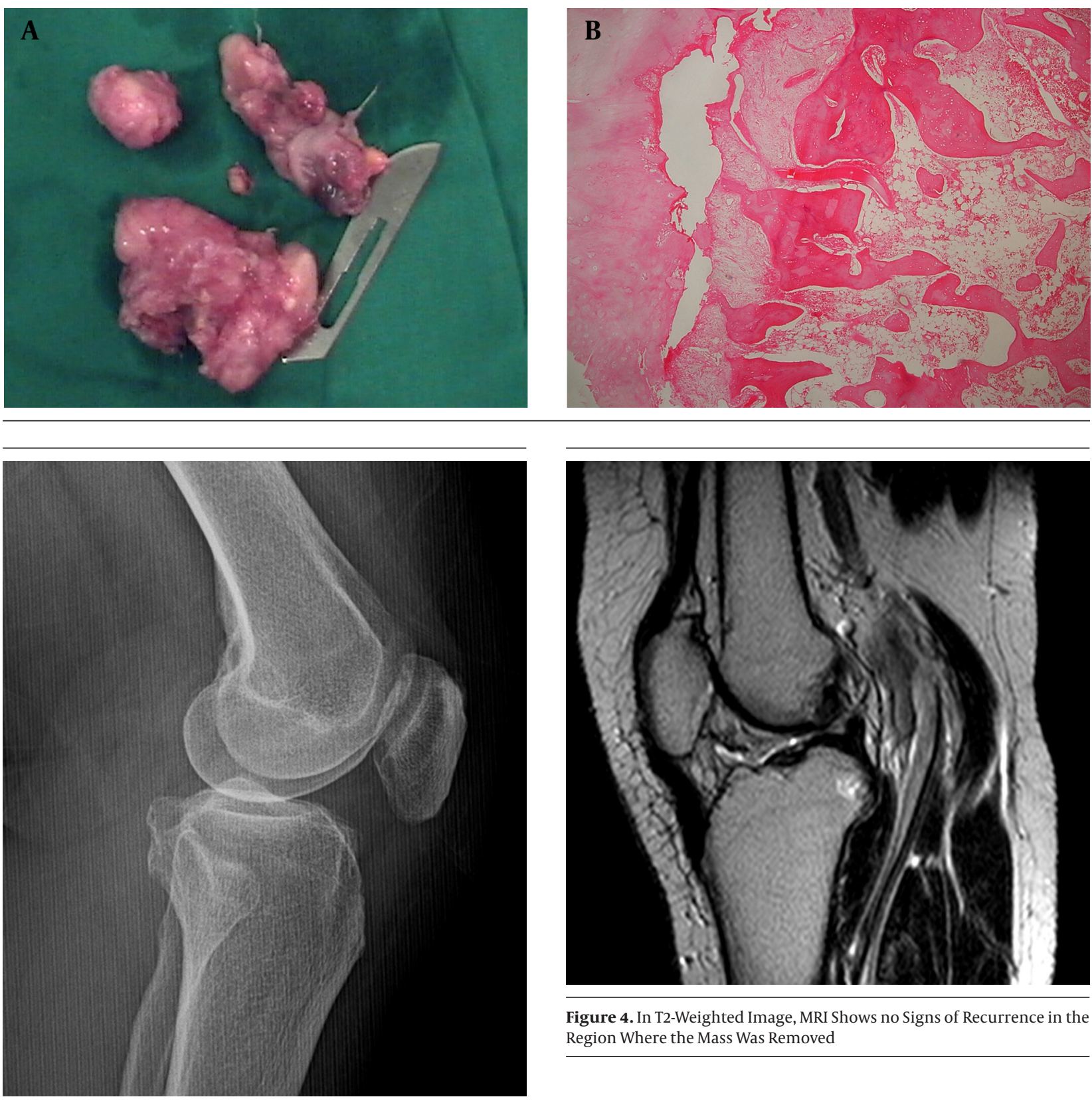

Figure 4. In T2-Weighted Image, MRI Shows no Signs of Recurrence in the Region Where the Mass Was Removed

Figure 3. Lateral Radiograph of the Knee Shows no Signs of Recurrence After a 10-Year Follow-up Period

Postoperative course was unremarkable. At the last follow-up visit in the tenth year, the patient had no clinical and radiographic evidence of recurrence with a full range of movement (Figures 3 and 4).

\section{Discussion}

The terminology and etiology of some para-articular masses are still confusing. Sakai et al. (7) reported three cases, two of which were classified as chondroma and one as osteochondroma on the basis of clinical, radiological and histological features of the cases. The first two cases were different from the last one as the patients demonstrated clinical symptoms before referring to the 
hospital; they had calcified soft tissue on X-ray, whereas the third case had osseous mass. Lastly, the first two masses consisted of mainly cartilaginous tissue while the mass in the third case was mainly formed of bone tissue with a relatively small amount of cartilaginous tissue (7). Cohen et al. (5) reported a post-traumatic intra-articular synovial osteochondroma which was free of attachments in the infrapatellar region. Essentially, the lesion was in the same area with the cases of Sakai et al.(7). The authors explained the lesion as phase 4 synovial chondromatosis, which occurred following a traumatic episode of years (5). The described mass here was also at the infrapatellar region, similar to the previous cases $(3,4)$. However, histologically the lesion was quite similar to the case classified as osteochondroma by Sakai et al. (7), except having a lobular pattern and was macroscopically very similar to the case described by Cohen et al. (5).

The cause of para-articular osteochondroma and chondroma is not known. Cohen et al. (5) additionally commented that previous trauma might be the origin of the pathology, and traumatic lesions have more osseous component in contrast to atraumatic, which have more cartilaginous lesions. Most of the previously reported cases, similar to the current study, did not follow trauma (4, 7-10). On the other hand, some authors believe that there is a cartilaginous metaplasia of the connective tissue with subsequent ossification (8). However, when the duration of mass and ossification is considered, they do not seem to be relevant (10). Krebs and Parker (6) established a relationship between Hoffa disease and paraarticular chondroma. The authors claimed that chronicle microtrauma such as repetitive impingement of the infrapatellar fat pad, might result in Hoffa's disease and subsequently chondroma (6). In the present case, there was no previous major or repetitive microtrauma however, contrary to the report of Sakai et al.(7), and the mass had significant osseous component. These findings show that the etiology is still obscure, but the appearance of all the lesions in the infrapatellar fad pad were mostly in the advanced ages, which prompt us to take metaplasia as etiology.

Osteochondroma are one of the most common tumors that usually originate in the metaphyseal areas of long bones. They present during rapid growing period and cease when growth slows down. On the contrary paraarticular osteochondroma, which is very rare, has no attachment to the bone and appears in advanced ages; in ostechonroma cases, malignant degeneration to chondrosarcoma should be considered. The entity, described in the current study, has benign clinical course with no report of recurrence after removal in an average twoyear follow-up (9). The current study finding was consistent with the literature with no recurrence after 10-year follow-up, which is the longest period in the literature. Due to non-existence of the stalk and the location in either the infrapatellar or intercondylar fat pad, fat tissue might be considered as origin of lesion, and osteochondroma might be a misleading nomenclature for that type of lesion, which is likely related to metaplasia $(7,9)$. Also in this case, the mass was completely replaced with fat pad and connected by surrounding tissue without any attachment in the surrounding osseous structure.

The findings support that infrapatellar osteocartilaginous masses, so called para-articular osteochondroma and chondroma, might originate in the soft tissue probably as a result of metaplasia; therefore, the para-articular chondroma and osteochondroma terminologies do not seem appropriate for these entities. Operative removal of the mass seems to be a curative treatment method according to the findings of the present case and literature.

\section{Acknowledgements}

The authors wish to thank Alyson Sarioglu for helping with preparation of the manuscript.

\section{Authors' Contributions}

Hasan Bombaci: developing original idea, data analysis, writing the manuscript; Emre Bilgin: preparing the manuscript.

\section{References}

1. Das AK, Mukherjee DR. Giant osteochondral loose body of the knee joint. A case report. J Bone Joint Surg Am. 1978;60(4):559-60.

2. Reith JD, Bauer TW, Joyce MJ. Paraarticular osteochondroma of the knee: report of 2 cases and review of the literature. Clin Orthop Relat Res.1997;(334):225-32.

3. Oliva F, Marconi A, Fratoni S, Maffulli N. Extra-osseous osteochondroma-like soft tissue mass of the patello-femoral space. BMC Musculoskelet Disord. 2006;7:57.

4. Singh R, Jain M, Siwach R, Rohilla S, Sen R, Kaur K. Large paraarticular osteochondroma of the knee joint: a case report. Acta Orthop Traumatol Turc. 2012;46(2):139-43.

5. Cohen AP, Giannoudis PV, Hinsche A, Smith RM, Matthews SJ. Post-traumatic giant intraarticular synovial osteochondroma of the knee. Injury. 2001;32(1):87-9.

6. Krebs VE, Parker RD. Arthroscopic resection of an extrasynovial ossifying chondroma of the infrapatellar fat pad: end-stage Hoffa's disease? Arthroscopy. 1994;10(3):301-4.

7. Sakai H, Tamai K, Iwamoto A, Saotome K. Para-articular chondroma and osteochondroma of the infrapatellar fat pad: a report of three cases. Int Orthop. 1999;23(2):114-7.

8. Bostman O, Karaharju E, Heikkonen L, Holmstrom T. Extraskeletal ossifying chondroma in the knee. A case report. Acta Orthop Scand. 1985;56(1):87-9.

9. Dienst M, Schneider G, Pahl S, Ensslin S, Kohn D. Intra-articular osteochondroma of the posterior cavity of the knee. Arch Orthop Trauma Surg. 2002;122(8):462-5

10. Milgram JW, Dunn EJ. Para-articular chondromas and osteochondromas: a report of three cases. Clin Orthop Relat Res. 1980;(148):147-51. 